\title{
Análise imunofenotípica de subpopulações linfocitárias do sangue periférico na esclerose sistêmica ${ }^{(*)}$
}

\section{Immunophenotypic analysis of lymphocyte subpopulations in the blood of systemic sclerosis patients}

\author{
Linete Parolin Ercole ${ }^{(1)}$, Mariester Malvezzi ${ }^{(2)}$, Antonio Carlos Boaretti ${ }^{(3)}$, \\ Shirley Ramos da Rosa Utiyama ${ }^{(4)}$, Acir Rachid ${ }^{(5)}$ e Sebastião Cezar Radominski ${ }^{(6)}$
}

\section{RESUMO}

A esclerose sistêmica (ES) é uma doença inflamatória crônica do tecido conjuntivo, de etiologia desconhecida, caracterizada por fibrose e dano microvascular dos órgãos afetados. Há várias evidências de que a ativação do sistema imune celular participa de maneira expressiva na sua patogênese. Objetivo: Analisar numericamente as subpopulações linfocitárias no sangue periférico de pacientes com ES e sua possível relação com fatores clínicos e laboratoriais. Métodos: Foram analisadas as subpopulações linfocitárias de 42 pacientes com ES e 28 controles normais, através da citometria de fluxo utilizando os antígenos linfocitários: $\mathrm{CD} 2$, CD3, CD4, CD8, CD19, CD25, CD45RA, CD56, CD71, HLA-DR, TCR $\alpha / \beta$ e TCR $\gamma / \delta$. Resultados: Nos pacientes com ES comparados com o grupo-controle, foram encontrados valores porcentuais normais para os linfócitos $\mathrm{T} C \mathrm{CD} 2+, \mathrm{CD} 3+, \mathrm{CD} 3+\mathrm{CD} 4+$, CD3+CD8+, CD25+, CD4+CD45RA+, CD8+CD45RA+, CD71+ e para a relação $\mathrm{CD} 4+/ \mathrm{CD} 8+$. Em contraste, os linfócitos $\mathrm{T}$ $\mathrm{CD} 3+\mathrm{TCR} \gamma / \delta+$ mostraram-se com porcentuais diminuídos nos pacientes com ES difusa, de longa duração, com envolvimento pulmonar caracterizado por doença pulmonar restritiva, envolvimento muscular e presença de anticorpo anti-Scl-70. Os pacientes com a forma difusa de ES apresentaram, tanto na fase recente como na tardia, aumento na porcentagem de linfócitos T CD4+ e CD8+ expressando moléculas de ativação HLA-DR. Na fase tardia da doença, não importando a forma clínica, foi encontrado aumento na porcentagem de linfócitos $T$ CD4+CD45RA+. Os pacientes com ES limitada e fase recente

\section{ABSTRACT}

Systemic sclerosis (SSc) is a chronic inflammatory connective tissue disease of unknown etiology characterized by fibrosis and microvascular injury in affected organs. It has become clear that the activation of cellular immune system plays a central role in the pathogenesis of SSc. Objective: The purpose of this study was to analyze numerically lymphocytic subpopulations in the blood of systemic sclerosis patients and their relations with clinical and laboratory manifestations. Methods: We studied a group of 42 patients with SSc and a group of 28 matched normal controls by flow cytometry using the following lymphocyte cell-surface markers: $C D 2$, CD3, CD4, CD8, CD19, CD25, CD45RA, CD56, CD71, HLA$D R, T C R \alpha / \beta$ and $T C R \gamma / \delta$. Results: SSc patients had similar percentages of $\mathrm{CD} 2+, \mathrm{CD} 3+, \mathrm{CD} 3+\mathrm{CD} 4+, \mathrm{CD} 3+\mathrm{CD} 8+, \mathrm{CD} 25+$, CD4+CD45RA+, CD8+CD45RA+, CD71+ cells and CD4+/ $\mathrm{CD} 8+$ cell ratio when compared to normal controls. In contrast, the percentages of TCR $\gamma / \delta$ cells were significantly lower in SSc patients with diffuse and late-stage disease with pulmonary and muscle involvement and the presence of anti-Scl-70 antibodies. Patients with diffuse SSc in early and late-stage disease had significantly increased percentages of HLA-DR in CD4+ and CD8+ cells; patients with late-stage disease had increased percentages of CD4+CD45RA $+T$ cells; patients with limited and early-stage disease had small

\footnotetext{
* Departamentos de Clínica Médica e de Patologia. Hospital de Clínicas da UFPR. Curitiba, PR. Recebido em 7/6/2002. Aprovado, após revisão, em 2/12/2002. 1. Professora assistente doutora da disciplina de Reumatologia da FEPAR.

2. Professora adjunta da disciplina de Hematologia; coordenadora do Laboratório de Imunofenotipagem do HC/UFPR.

3. Professor titular da disciplina de Patologia Médica - UFPR.

4. Professora adjunta da disciplina de Patologia Médica - UFPR.

5. Professor sênior do Departamento de Clínica Médica - UFPR.

6. Professor adjunto da disciplina de Reumatologia - UFPR.
}

Endereço para correspondência: Linete Parolin Ercole. Rua Benedito Soares Pinto, 2.123, CEP 83601-040, Campo Largo, PR. 
mostraram diminuição na porcentagem dos linfócitos B CD19+. Os pacientes com doença difusa e fase tardia apresentaram diminuição na porcentagem dos linfócitos NK CD56+. Conclusões: Estes resultados sugerem que as alterações dos linfócitos T, B e NK possam estar envolvidas no processo de desencadeamento e/ou perpetuação da ES, havendo a possibilidade de ter utilidade prognóstica em alguns grupos de pacientes.

Palavras-chave: esclerose sistêmica, linfócitos $\mathrm{T}$, linfócitos gama/delta, autoimunidade, imunofenotipagem.

\section{INTRODUÇÃO}

A esclerose sistêmica (ES) é uma doença inflamatória crônica do tecido conjuntivo, de etiologia desconhecida, caracterizada por fibrose e dano microvascular dos órgãos afetados, apresentando diversas manifestações clínicas e laboratoriais com curso e prognóstico variáveis. Ainda que a etiologia e a patogênese da ES permaneçam obscuras, existem muitas evidências que a ativação dos sistemas imunes celular e humoral, que é evento precoce nessa doença, participe de maneira muito intensa nestes processos. Com a ativação do sistema imune celular, os linfócitos e seus produtos solúveis, incluindo as citoquinas e os autoanticorpos, podem ativar ou destruir as células endoteliais, os fibroblastos e a síntese de colágeno. Desta maneira o sistema imune pode causar dano tecidual nos pacientes com ES ${ }^{(1-4)}$.

Estudos demonstram que os linfócitos $\mathrm{T}$ ativados na fase inicial da doença migram infiltrando a pele e os órgãos internos. O predomínio de subpopulações distintas de linfócitos $\mathrm{T}$ na pele $(\mathrm{CD} 4+)$ e no pulmão $(\mathrm{CD} 8+)$ de pacientes com ES sugere que diferentes linfócitos $\mathrm{T}$ possam contribuir para o processo de doença em diferentes órgãos ${ }^{(4-10)}$

Outras evidências da ativação imune na ES são os achados de mediadores solúveis (citoquinas) em grandes quantidades, incluindo a interleucina-2, a interleucina- 4 , a interleucina-6, a interleucina-12 e o fator de necrose tumoral-a (TNF- $\alpha$ ). Todos estes mediadores podem ser produzidos pelos linfócitos $\mathrm{T}$ ou outras células inflamatórias $^{(3,4,6,11)}$.

Os linfócitos B também são ativados precocemente, levando à hipergamaglobulinemia e à produção de auto-anticorpos, como o anti-topoisomerase I (anti-Scl-70), o anticentrômero e o anti-RNA polimerase I e III, que são encontrados com freqüência e considerados relativamente específicos para a $\mathrm{ES}^{(3,4,6)}$. percentages of $B$ cells (CD19+): and patients with diffuse and late-stage disease had small percentages of $N K$ cells $(C D 56+)$. Conclusions: These results suggest that $T, B$ and NK cell alterations may be involved in the onset of the disease and/or in the perpetuation of disease, and may eventually be useful as a prognostic indicator in selected patient subgroups.

Keywords: systemic sclerosis, $T$ cells, gamma/delta cells, autoimmunity, immunophenotypic analysis.

O estudo das populações de linfócitos no sangue de pacientes com ES tem apresentado resultados conflitantes por causa dos diferentes métodos empregados e dos diferentes critérios de seleção dos pacientes ${ }^{(12-15)}$. Com a disponibilidade dos anticorpos monoclonais e da citometria de fluxo tornou-se possível a determinação do fenótipo das células de acordo com as suas populações funcionalmente distintas ${ }^{(6,16-18)}$.

No presente estudo, foram analisadas as subpopulações linfocitárias no sangue periférico de pacientes com ES, nas formas clínicas limitada e difusa, juntamente com sua correlação com o tempo de doença, manifestações clínicas e presença de auto-anticorpos, um trabalho inédito na população brasileira.

\section{PACIENTES E MÉTODOS}

Foram estudados 42 pacientes com ES definidos de acordo com os critérios do Colégio Americano de Reumatologia $^{(19)}$, atendidos no ambulatório de reumatologia do Hospital de Clínicas da Universidade Federal do Paraná. Entre estes, 38 eram mulheres e 4 homens, 38 eram brancos e 4 negros; a idade de início da doença variou de 11 a 54 anos (média: 37,5 anos); a duração da doença variou de 1 a 30 anos (média: 6,1 anos). Vinte e três apresentaram a forma difusa e 19 a forma limitada ${ }^{(20)}$. Os pacientes foram divididos quanto à duração da doença: menos de 3 anos como doença recente e mais de 3 anos como doença tardia ${ }^{(21)}$, resultando em 16 pacientes com ES recente e 26 com ES tardia. Nenhum dos pacientes estava recebendo terapia imunossupressora. Foram incluídos apenas os pacientes em uso de prednisona em doses baixas $(<10 \mathrm{mg} / \mathrm{d})$. Foram estudados 28 controles normais, indivíduos sadios, sem evidência de doença reumática; sendo 20 mulheres e 8 homens, a idade variou de 27 a 53 anos (média: 37 anos), 25 brancos e 3 negros. 


\section{ANTICORPOS ANTINUCLEARES (ANA)}

Os ANA foram determinados pela técnica de imunofluorescência indireta usando como substrato células HEp-2. O anticorpo anticentrômero foi detectado da mesma forma. Um padrão nuclear nítido na diluição de 1:40 foi considerado positivo ${ }^{(22-24)}$. O anticorpo anti-Scl-70 foi detectado por ELISA, utilizando o Kit Hemagem (São Paulo, Brasil) ${ }^{(24)}$. Os anticorpos anti-RNP, anti-Sm, anti-Ro e anti-La foram detectados através da técnica de imunodifusão dupla de Ouchterlony, utilizando como substrato o extrato de baço de vitelo (Escola Paulista de Medicina, Brasil) ${ }^{(25)}$.

\section{SUBPOPULAÇÕES LINFOCITÁRIAS}

As amostras de sangue foram coletadas em anticoagulante EDTA e ajustadas com concentração final de $1 \times 10^{6}$ células/ $\mathrm{ml}$. Foram coradas pela técnica de "cora-lisa", usando imunofluorescência direta (com exceção do CD45RA, onde foi realizada imunofluorescência indireta). Os antígenos de expressão foram analisados utilizando os anticorpos monoclonais apresentados na Tabela 1. Os anticorpos monoclonais foram previamente conjugados com os fluorocromos isotiocianato de fluoresceína (FITC), ficoeritrina (PE) e ficoeritrina/cianina5 (PECy5) ou peridina clorofilada (PerCP) ou terceira cor (TC): 1) IgG1/IgG1/IgG1 (FITC/PE/PECy5), HLA-DR (PE) e CD4/CD8/CD3 (FITC/PE/PECy5) adquirido de Immunotech (França); 2) CD45RA (PURO), CD25 (FITC),CD8/HLA-DR (FITC/PE), CD4 (FITC), CD71(FITC), CD56 (PE), HLA-DR (PerCP), TCR $\alpha / \beta$ (FITC) e TCR $\gamma / \delta$ (PE) obtido da Becton Dickinson (EUA); 3) CD4 (PE), CD19 (PECy5), CD2 (PE) e CD45 (FITC) adquirido da DAKO (Dinamarca) e 4) CD8 (TC) e CD3 (TC) obtido da CALTAG (EUA). Brevemente, $100 \mu \mathrm{l}$ das amostras foram incubadas por 15 minutos à temperatura ambiente, no escuro, na presença de $10 \mu \mathrm{l}$ de cada anticorpo monoclonal de acordo com titulação prévia. Após, foi adicionado $1 \mathrm{ml}$ de solução de FACS lysin (Becton Dickinson) diluída 1/10 (v/v) em água destilada, e a seguir nova incubação por 10 minutos à temperatura ambiente, no escuro, para lisar as hemácias. As células foram centrifugadas ( 5 minutos a $2000 \mathrm{rpm}$ ) e o botão de células foi lavado com $3 \mathrm{ml}$ de PBS. Finalmente, as células foram ressuspensas em $1 \mathrm{ml}$ de PBS para serem analisadas no citômetro. A aquisição foi realizada no citômetro de fluxo FACS Vantage (Becton Dickinson) equipado com o feixe de laser "INNOVA Enterprise Ion Laser", que produz um feixe de $488 \mathrm{~nm}$ na potência de $80 \mathrm{~mW}$. A calibração do aparelho foi realizada antes da aquisição dos dados utilizando-se protocolos previamente estabelecidos. Foram adquiridos 15.000 eventos por tubo e analisados pelo programa Paint-A-Gate PRO (Becton Dickinson) ${ }^{(26)}$.

\section{ANÁLISE ESTATÍSTICA}

Para comparações entre os grupos de pacientes e controles foi utilizado o teste não paramétrico de Mann-Whitney. Para amostras independentes foi utilizado o teste " $t$ de Student".

\section{RESULTADOS}

COMPARAÇÃO ENTRE AS SUBPOPULAÇÕES LINFOCITÁRIAS DO GRUPO DE PACIENTES COM ES E DO GRUPO-CONTROLE

Encontrou-se aumento estatisticamente significativo nas porcentagens dos marcadores de ativação de linfócitos T CD4+HLA-DR+ $(p<0,05)$ e CD8+HLA-DR + $(\mathrm{p}<0,01)$ no sangue periférico dos pacientes com ES com relação aos do grupo-controle, enquanto que a proporção de linfócitos $\mathrm{T}$ CD $3+\mathrm{TCR} \gamma / \delta+(\mathrm{p}<0,05)$ esteve significativamente diminuída. Também observaram-se diminuídas as

TABEla 1

ANTICORPOS MONOCLONAIS E AS SUBPOPULAÇÕES LINFOCITÁRIAS CORRESPONDENTES

\begin{tabular}{|c|c|}
\hline $\begin{array}{l}\text { Anticorpos } \\
\text { monoclonais }\end{array}$ & $\begin{array}{l}\text { Subpopulações } \\
\text { linfocitárias }\end{array}$ \\
\hline $\mathrm{CD} 3+$ & Pan linfócito T \\
\hline $\mathrm{CD} 3+\mathrm{CD} 4+$ & Linfócito T auxiliador/indutor \\
\hline $\mathrm{CD} 3+\mathrm{CD} 8+$ & Linfócito T supressor/citotóxico \\
\hline $\mathrm{CD} 3+\mathrm{CD} 4+\mathrm{CD} 8+$ & Linfócito T com dupla expressão positiva \\
\hline $\mathrm{CD} 3+\mathrm{CD} 4-\mathrm{CD} 8-$ & Linfócito T com dupla expressào negativa \\
\hline CD45RA+ & Molécula acessória de ativação \\
\hline CD4+CD45RA+ & Linfócito T auxiliador virgem \\
\hline CD8+CD45RA+ & Linfócito T supressor virgem \\
\hline $\mathrm{CD} 25+$ & Molécula acessória de ativação - receptor IL-2 \\
\hline CD4+CD25+ & Linfócito T auxiliador ativado \\
\hline CD8+CD25+ & Linfócito T supressor ativado \\
\hline CD4+HLA-DR+ & Linfócito T auxiliador ativado com receptor $\mathrm{CPH}$ \\
\hline CD8+HLA-DR+ & Linfócito T supressor ativado com receptor CPH \\
\hline $\mathrm{CD} 3+\mathrm{TCR} \alpha / \beta$ & Receptor linfócito T a/b \\
\hline CD3+TCR $\gamma / \delta$ & Receptor linfócito $\mathrm{Tg} / \mathrm{d}$ \\
\hline $\mathrm{CD} 2+$ & Pan linfócito T \\
\hline CD71+ & Molécula acessória de ativação - receptor transferrina \\
\hline CD19+ & Pan linfócito B \\
\hline CD56+ & Linfócito NK \\
\hline
\end{tabular}


porcentagens de linfócitos CD19+ $(\mathrm{p}<0,05)$ e CD56+ $(\mathrm{p}<0,01)$ no grupo com ES, sendo estatisticamente significativa esta diferença com o grupo-controle.

\section{CORRELAÇÃO ENTRE AS SUBPOPULAÇÕES LINFO- CITÁRIAS E AS FORMAS CLÍNICAS DA ES}

Ao serem comparadas as subpopulações de linfócitos dos pacientes com ES difusa e do grupo-controle, observou-se aumento no porcentual dos linfócitos $\mathrm{T}$ com marcadores de ativação CD4+HLA-DR+ $(p<0,01)$ e CD8+HLA-DR+ $(p<0,001)$. Os linfócitos T com expressão CD3+TCR $\gamma / \delta+$ $(p<0,01)$ estavam em proporções diminuídas, assim como os linfócitos NK CD56+ $(\mathrm{p}<0,01)$.

Foram também comparadas as subpopulações linfocitárias dos pacientes com a forma limitada da ES e do grupocontrole. Foi encontrado aumento na população de linfócitos T CD3+CD4+ $(\mathrm{p}<0,05)$, com diminuição dos linfócitos CD19+ $(\mathrm{p}<0,05)$ no grupo de pacientes.

Quando foram correlacionadas as subpopulações linfocitárias das formas clínicas difusa e limitada da ES, observou-se diminuição das porcentagens de linfócitos $\mathrm{T} \mathrm{CD} 3+\mathrm{CD} 4+(\mathrm{p}<0,05)$ na forma difusa e aumento de linfócitos $\mathrm{T}$ CD4+HLA-DR+ $(\mathrm{p}<0,01)$ na forma difusa.

\section{CORRELAÇÃO ENTRE AS SUBPOPULAÇÕES LINFO- CITÁRIAS E A DURAÇÃO DA ES}

Quando comparou-se as subpopulações linfocitárias dos pacientes com ES recente com as do grupo-controle, encontrou-se aumento do marcador de ativação CD8+HLA-DR+ $(p<0,05)$ e diminuição dos linfócitos B CD19+ $(p<0,05)$.

Com relação à ES fase tardia, quando comparadas as subpopulações destas com as do grupo-controle, foi observado aumento dos linfócitos T CD3+CD4+ $(\mathrm{p}<0,05)$ e diminuição dos linfócitos T CD $3+T C R \gamma / \delta+(p<0,05)$. Das moléculas de ativação observou-se aumento dos linfócitos T CD4+CD45RA+ $(p<0,05)$, CD4+HLA-DR + $(p<0,05)$ e CD8+HLA-DR + $(p<0,01)$. Os linfócitos NK CD56+ $(\mathrm{p}<0,01)$ estavam diminuídos.

$\mathrm{Na}$ ES recente foram maiores as porcentagens de linfócitos NK CD56+ $(p<0,01)$ quando comparadas com as encontradas nos pacientes com ES tardia.

CORRELAÇÃO ENTRE AS SUBPOPULAÇÕES LINFOCITÁRIAS E A PRESENÇA DE ANTICORPO ANTI-SCL-7O Nos pacientes portadores de anticorpo anti-Scl-70 constatou-se a diminuição dos linfócitos T CD3+TCR $\gamma / \delta+$ $(\mathrm{p}<0,05)$ quando comparados com os pacientes sem este anticorpo.
CORRELAÇÃO ENTRE AS SUBPOPULAÇÕES LINFOCITÁRIAS E A PRESENÇA DE ANTICORPO ANTICENTROAMERO

Foi encontrada a diminuição das moléculas de ativação dos linfócitos T CD4+HLA-DR+ $(\mathrm{p}<0,05)$ nos pacientes com ES portadores de ACA quando comparados com os pacientes com ES sem ACA.

CORRELAÇÃO ENTRE AS SUBPOPULAÇÕES LINFOCITÁRIAS E AS MANIFESTAÇÕES CLÍNICAS DA ES

Foi observada associação estatisticamente significativa entre os pacientes que apresentavam comprometimento pulmonar - do tipo doença pulmonar restritiva (DPR) $(\mathrm{p}<0,05)$ - e comprometimento muscular $(\mathrm{p}<0,05)$ com a diminuição de linfócitos T CD3+TCR $\gamma / \delta+(p<0,05)$.

As manifestações clínicas articular, cutânea, vascular, pulmonar do tipo HP, cardíaca e renal não apresentaram correlação estatística significativa com as subpopulações linfocitárias.

$\mathrm{Na}$ Tabela 2 encontram-se resumidos os fenótipos dos linfócitos do sangue periférico dos pacientes estudados com ES.

\section{DISCUSSÃo}

Nos pacientes com ES os antígenos de superficie que caracterizam a linhagem linfóide $\mathrm{T}(\mathrm{CD} 2+, \mathrm{CD} 3+$, $\mathrm{CD} 3+\mathrm{CD} 4+$ e $\mathrm{CD} 3+\mathrm{CD} 8+$ ) apresentaram valores porcentuais normais quando comparados com o grupo-controle. Estes achados são condizentes com os relatos de Bruns et al. ${ }^{(17)}$, porém discordam dos achados de Frieri et al. ${ }^{(27)}$, onde os valores de CD3+ e CD8+ estavam diminuídos, mas o CD4+ estava aumentado. A razão CD4+/CD8+ também esteve normal nos pacientes com ES em estudo, discordando de vários autores ${ }^{(14,16,28-30)}$ que encontraram aumento nesta razão com relação aos controles, sugerindo que a redução do número de células CD8+ possa ser causada também pela diminuição do número de linfócitos NK, pois estas células também apresentam o antígeno CD8 em sua superfície. Uma explicação para esta diversidade de achados pode ser a diferença na própria seleção dos pacientes, quanto ao estágio, forma clínica, duração e tratamento da doença, o que torna difícil avaliar o envolvimento celular imune de forma comparativa nos diferentes trabalhos.

Observou-se nos pacientes com ES limitada e forma tardia da doença, aumento estatisticamente significativo dos linfócitos $\mathrm{T}$ CD3+CD4+ quando correlacionadas com as subpopulações que caracterizam a linhagem de linfócitos $\mathrm{T}$ com as formas clínicas e o tempo de doença. 
$\mathrm{Na}$ avaliação dos linfócitos T expressando TCR $\gamma / \delta$ foi encontrada diminuição estatisticamente significativa nos portadores da doença em comparação com os controles. A maioria dos linfócitos $\mathrm{T}$ maduros expressam em sua membrana o TCR $\alpha / \beta$ que está associado com o complexo CD3 e aproximadamente 5\% dos linfócitos T expressam o TCR $\gamma$ / $\delta$. Estes linfócitos T expressando o TCR $\gamma / \delta$ agem na homeostase da resposta imune e parecem estar envolvidos em várias condições como as imunodeficiências, infecções e doenças autoimunes ${ }^{(31,32)}$. Também parecem exercer função reguladora nos tecidos durante a resposta imune, sendo encontrada deposição destas células nas áreas perivasculares nos estágios iniciais da ES e em menor grau, nas fases escleróticas crônicas. Foi sugerido que estes linfócitos $\mathrm{T}$ CD3 $+\mathrm{TCR} \gamma / \delta+$ possam estar envolvidos na patogênese da lesão cutânea e de outros órgãos na ES, tanto no início como na perpetuação da doença ${ }^{(32,33)}$.

Os achados de diminuição dos linfócitos T CD3+TCR $\gamma / \delta+$ neste trabalho concordam com os relatos de alguns autores ${ }^{(6,21)}$, que sugerem que o subtipo de linfócitos $\mathrm{T}$ pode desempenhar papel na ES. Provavelmente a redução dos linfócitos T $\mathrm{CD} 3+\mathrm{TCR} \gamma / \delta+$ na circulação seja causada pelo recrutamento destes linfócitos nos tecidos dos pacientes para a manutenção do processo de atividade da doença, pois os mesmos estão relacionados com o equilíbrio da resposta imune.

A partir da análise, neste estudo, dos parâmetros clínicos e da apresentação dos linfócitos T CD $3+\mathrm{TCR} \gamma / \delta+$, observou-se uma diminuição estatisticamente significativa destes linfócitos nos pacientes portadores de ES difusa, de longa duração, com envolvimento pulmonar caracterizado por DPR, envolvimento muscular e presença de anticorpo antiScl-70. Esta população pode ser considerada como um grupo especial de pacientes com manifestações imunes semelhantes, pois é bem fundamentada na literatura que a ES difusa tem relação com a presença de anticorpo anti-Scl70 e com o envolvimento pulmonar ${ }^{(34,35)}$. Este achado pode sugerir que os linfócitos T CD $3+\mathrm{TCR} \gamma / \delta+$ neste grupo de pacientes possa estar envolvido na perpetuação da lesão na ES. Holcombe et al. ${ }^{(21)}$ também encontraram diminuição mais evidente do linfócito T CD $3+\mathrm{TCR} \gamma / \delta+$ nos pacientes com ES difusa e presença de anticorpo anti-Scl-70, porém discordam do resultado deste estudo quanto ao tempo de doença, pois encontraram maior freqüência desta alteração nos pacientes com doença recente.

TABELA 2

CARACTERÍSTICAS FENOTÍPICAS DOS LINFÓCITOS NOS PACIENTES COM ES

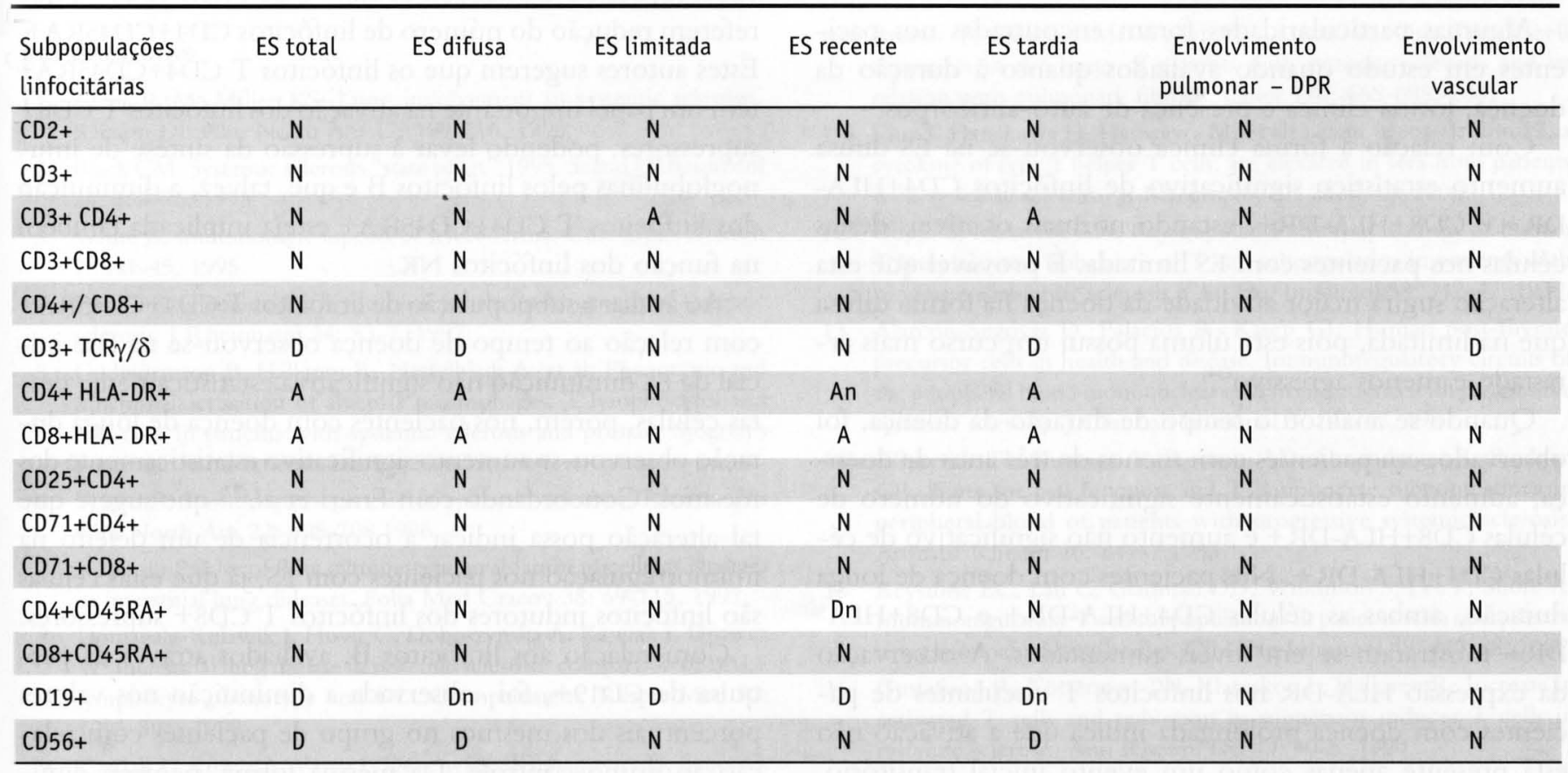

$\mathrm{N}=$ normal comparado com o controle; $\mathrm{D}=$ diminuído comparado com o controle $(p<0,05) ; A=$ aumentado comparado com os controles ( $<<0,05)$; $\mathrm{D} n=$ diminuído comparado com 0 controle sem significado estatístico; An=aumentado comparado com o controle sem significado estatístico. 
O aparecimento de linfócitos T ativados na circulação é um achado comum nos pacientes com doenças autoimunes. Na ES, como uma destas doenças, a presença de linfócitos $\mathrm{T}$ ativados provavelmente implica na continuação das reações imunes dependentes de linfócitos $\mathrm{T}$ em todo o corpo. A natureza do processo de ativação na ES é desconhecido, mas o mecanismo de ativação parece estar presente durante os estágios iniciais da doença e persiste com a evolução da mesma ${ }^{(10,16)}$.

As proteínas de adesão na superfície dos linfócitos, também conhecidas como moléculas acessórias, podem ser responsáveis pelas diferentes condições de ativação e função efetora dos linfócitos T CD4+ e CD8+ ${ }^{(36)}$. As diferentes expressões de algumas moléculas de ativação nos linfócitos T CD4+ e CD8+ como HLA-DR (receptor do Complexo Principal de Histocompatibilidade Classe II), CD25 (cadeia $\alpha$ do receptor de interleucina-2), CD71 (receptor da transferrina) e CD45RA (célula $T$ virgem) são utilizadas para avaliar a ativação dos linfócitos $T$ no sangue periférico dos pacientes com ES.

Neste estudo, observou-se aumento estatisticamente significativo dos níveis de linfócitos CD4+HLA-DR+e CD8+HLA-DR+ nos pacientes com ES quando comparados com o grupo-controle, indicando que os linfócitos $\mathrm{T}$ estão ativados nestes pacientes e, portanto, podem participar no mecanismo da doença. Tais achados concordam com relatos de outros autores ${ }^{(6,16,30,36)}$.

Algumas particularidades foram encontradas nos pacientes em estudo quando avaliados quanto à duração da doença, forma clínica e presença de auto-anticorpos.

Com relação à forma clínica observou-se na ES difusa aumento estatístico significativo de linfócitos CD4+HLA$\mathrm{DR}+$ e CD8+HLA-DR+, estando normais os níveis destas células nos pacientes com ES limitada. É provável que esta alteração sugira maior atividade da doença na forma difusa que na limitada, pois esta última possui um curso mais arrastado e menos agressivo ${ }^{(34)}$.

Quando se analisou o tempo de duração da doença, foi observado, em pacientes com menos de três anos de doença, aumento estatisticamente significativo do número de células CD8+HLA-DR+ e aumento não significativo de células CD4+HLA-DR+. Nos pacientes com doença de longa duração, ambas as células CD4+HLA-DR+ e CD8+HLA$\mathrm{DR}+$ mostraram-se em níveis aumentados. A observação da expressão HLA-DR nos linfócitos T circulantes de pacientes com doença prolongada indica que a ativação não está presente apenas como um evento inicial transitório, mas é mantida através de todos os estágios da doença ${ }^{(16)}$.
Nos pacientes portadores de ES com anticorpo anticentrômero presente, observou-se diminuição estatisticamente significativa de células CD4+HLA-DR+, o que pode estar relacionado com a atividade geralmente mais branda da doença em presença deste anticorpo, que é característico da forma limitada, uma forma quase sempre menos agressiva ${ }^{(34)}$, porém, o número encontrado de pacientes foi pequeno para maiores considerações.

As moléculas de ativação CD25 e CD71 não se apresentaram alteradas nos linfócitos T CD4+ e CD8+ dos pacientes com ES, quando comparados com ogrupo-controle, diferindo de outros relatos onde ocorreu aumento nestes marcadores de ativação ${ }^{(6,17,30,36)}$.

A expressão da isoforma CD45RA do CD45, que representa os linfócitos $\mathrm{T}$ virgens, ou seja, aqueles que nunca encontraram antígeno, foi avaliada nos linfócitos T CD4+ e CD8+. Observou-se níveis normais de linfócitos $\mathrm{T}$ CD4+CD45RA+ e CD8+CD45RA+ nos pacientes com ES quando comparados com o grupo-controle. No estudo de Kahan et al. ${ }^{(37)}$, também não ocorreu variação de linfócitos T CD4+CD45RA+ com relação ao grupo-controle, contudo, os valores para a subpopulação de linfócitos $\mathrm{T}$ CD8+CD45RA+ foram significativamente maiores no grupo com ES. Para Fiocco et al. ${ }^{(36)}$, os pacientes com ES também não apresentaram variação quanto ao número de linfócitos $\mathrm{T}$ CD4+CD45RA+, o que não ocorreu com as observações de Gustafsson et al. ${ }^{(16)}$ e de Frieri et al. ${ }^{(27)}$, que referem redução do número de linfócitos CD4+CD45RA+. Estes autores sugerem que os linfócitos T CD4+CD45RA+ têm um papel importante na ativação dos linfócitos T CD8+ supressores, podendo levar à supressão da síntese de imunoglobulinas pelos linfócitos B e que, talvez, a diminuição dos linfócitos T CD4+CD45RA+ esteja implicada também na função dos linfócitos NK.

Ao avaliar a subpopulação de linfócitos T CD4+CD45RA+ com relação ao tempo de doença observou-se na fase inicial da ES diminuição não significativa estatisticamente destas células, porém, nos pacientes com doença de longa duração observou-se aumento significativo estatisticamente dos mesmos. Concordando com Frieri et al. ${ }^{(27)}$ que sugere que tal alteração possa indicar a ocorrência de um defeito na imunorregulação nos pacientes com ES, já que estas células são linfócitos indutores dos linfócitos T CD8+ supressores.

Com relação aos linfócitos $\mathrm{B}$, avaliados através da pesquisa de CD19+, foi observada a diminuição nos valores porcentuais dos mesmos no grupo de pacientes com relação ao grupo-controle. Da mesma forma, ocorreu diminuição estatística significativa dos linfócitos B nos pacientes 
com ES limitada e naqueles com doença recente, como também, foi observada a diminuição não significativa estatisticamente nestes linfócitos nos pacientes com ES difusa e naqueles com doença tardia, como referido por outros autores ${ }^{(27)}$. Entretanto, encontramos relatos de aumento dos valores percentuais de linfócitos B CD19+ nos pacientes com ES quando comparados com o grupo-controle, demonstrando que pequenas alterações na expressão de CD19+ podem induzir a produção de auto-anticorpos ${ }^{(38)}$, pois, a molécula de superfície CD19 funcionaria como uma proteína especializada que regula a sinalização dos linfócitos B e a produção de autoanticorpos ${ }^{(39)}$.

Outra subpopulação de linfócitos analisada foi a dos linfócitos NK, que se apresentaram em números porcentuais diminuídos quando avaliados pelo $\mathrm{CD} 56+$ nos pacientes com ES, concordando com os achados de outros autores $^{(27)}$. Porém, em outros estudos não há referência quanto a variação do número de linfócitos $\mathrm{NK}^{(21,30,40)}$, enquanto que em outros relatos há aumento do número de linfócitos NK CD56+, sugerindo que estes linfócitos participariam na modulação da função dos linfócitos $\mathrm{B}$, diversamente do que fazem os linfócitos NK CD16+(41). Estas variações entre os resultados podem ser causadas pela utilização de diferentes anticorpos na identificação da população de linfócitos com atividade $\mathrm{NK}^{(21,27)}$.

\section{REFERÊNCIAS}

1. Silver R M, Miller KS: Lung involvement in systemic sclerosis. Rheum Dis Clin North Am 17: 199-216, 1990.

2. Black CM: Systemic sclerosis "state of art" 1995. Scand J R heumatol 24: 194-96, 1995

3. White B: Immunologic aspects of scleroderma. Curr Opin Rheum 7: 541-45, 1995

4. Furst DE, Clements PJ: Hypothesis for the pathogenesis of systemic sclerosis. J Rheumatol 24: 53-7, 1997.

5. Gudbjörnsson B, Hällgren R, Nettelbladt A, et al: Phenotypic and functional activation of alveolar macrophages, $\mathrm{T}$ lymphocytes and NK cells in patients with systemic sclerosis and primary Sjögren's syndrome. Ann Rheum Dis 53: 574-79, 1994.

6. White B: Immunopathogenesis of systemic sclerosis. Rheum Dis Clin North Am 22: 695-708,1996.

7. Kopinski P: Use of flow cytometry in evaluation of cellular changes in interstitial lung dideases. Folia Med Cracov 38: 69-115, 1997.

8. Domagala-Kulawik J, Hoser G, Doboszynska A, Kawiak J, Droszcz W: Interstitial lung disease in systemic sclerosis: comparison of BALF lymphocyte phenotype and DLCO impairment. Respir Med 92: 1295-301, 1998.

9. Czirjak L, Koncz A, Varga I, Devenyi K, Kumanovics G, Szues G: Investigation of the alveolar macrophages and $\mathrm{T}$ lymphocytes in 15 patients with systemic sclerosis. Clin Rheumatol 18: 357-63, 1999.
Avaliando a forma clínica e o tempo de duração da ES com o comportamento dos linfócitos NK CD56+, observou-se diminuição destes nos pacientes com ES difusa e doença prolongada, porém, na forma limitada e fase recente da ES não ocorreu variação destes linfócitos. Estas alterações podem refletir um subgrupo específico da doença ou então um defeito não definido na função dos linfócitos $\mathrm{NK}^{(21,27,42)}$

Em uma análise global das subpopulações linfocitárias na ES foi possível concluir que estes dados fornecem indicações importantes para sugerir que a imunidade mediada por células esteja envolvida no processo de desencadeamento e manutenção da ES. Tais evidências são a presença de ativação dos linfócitos $\mathrm{T}$, através dos marcadores HLA-DR e CD45RA+, e a redução dos linfócitos T CD3+TCR $\gamma / \delta+$, dos linfócitos B e dos linfócitos NK.

$\mathrm{O}$ achado de um subgrupo particular formado por pacientes com ES difusa, de longa duração, com envolvimento pulmonar (DPR) e muscular e presença de anticorpo anti-Scl-70, relacionados com a redução dos linfócitos T CD $3+$ TCR $\gamma / \delta+$, pode sugerir que a avaliação das subpopulações linfocitárias possa servir como marcadores para o prognóstico destes pacientes. Para verificar tais suposições seria de valia realizar acompanhamento de tais subgrupos.

10. Bresser P, Jansen HM, Weller FR, Lutter R, Out TA: T-cell activation in the lungs of patients with systemic sclerosis and its relation with pulmonary fibrosis. Chest 120: 66S-68S, 2001.

11. Sato S, Hanakawa $H$, Hasegawa $M$, et al: Levels of interleukin 12, a cytokine of type 1 helper $\mathrm{T}$ cells, are elevated in sera from patients with systemic sclerosis. J. Rheumatol 27: 2838-42, 2000.

12. Gupta S, Malayiva AN, Rajagopolan P: Subpopulations of human $\mathrm{T}$ lymphocytes. Imbalance of $\mathrm{T}$ cell subpopulatios in patients with progressive systemic sclerosis. Clin Exp Immunol 38: 342-47, 1979.

13. Alarcón-Segovia D, Palacios R, Kasep GI: Human post-thymic precursor cells in health and disease. Immunoregulatory circuits of the peripheral blood mononuclear cells from patients with progressive systemic sclerosis. J Clin Lab Immunol 5: 143-48, 1981.

14. Whiteside TL, Kumagai Y, Roumm AD, Almendinger R, Rodnan GP: Supressor cell function and $\mathrm{T}$ lymphocyte subpopulations in peripheral blood of patients with progressive systemic sclerosis. Arthritis Rheum 26: 841-7,1983.

15. Keystone EC, Lau C, Gladman DD, Wilkinson S, Lee P, Shore A: Immunoregulatory $\mathrm{T}$ cell subpopulations in patients with scleroderma using monoclonal antibodies. Clin Exp Immunol 48: 443-88, 1982.

16. Gustafsson R, Tötterman TH, Klareskog L, Hällgren R: Increase in activated $\mathrm{T}$ cells and reduction in supperssor inducer $\mathrm{T}$ cells in systemic sclerosis. Ann Rheum Dis 49: 40-5, 1990.

17. Bruns M, Herrmann K, Haustein UF: Immunologic parameters in systemic sclerosis. Int J Dermatol 33: 25-32,1994. 
18. Dalkilic E, Dilek K, Gullulu M, et al: Lymphocyte phenotypes in systemic sclerosis. Ann Rheum Dis 58: 719-20, 1999.

19. Masi A T, Rodnan GP, Medsger Jr TA, et al: Preliminary criteria for the classification of systemic sclerosis (scleroderma). Arthritis Rheum 23: 581-90, 1980.

20. LeRoy EC, Black C, FleischmajerR, et al: Scleroderma (systemic sclerosis): classification, subsets and pathogenesis. J. Rheumatol 15: 202-5,1988.

21. Holcombe RF, Baethge BA, Wolf RE, Betzing KW, Steeart RM: Natural killer cells and gd $\mathrm{T}$ cells in scleroderma: relationship to disease duration and anti-Scl-70 antibodies. Ann Rheum Dis 54: 69-72, 1995.

22. Tan EM, Christia C, HolmanHR, et al: Anti-tissue antibodies in rheumatic disease standardization and nomenclature. Arthritis Rheum 20: 1419-20, 1977.

23. Molden DP, Nakamura RM, Tan EM: Standardization of the immunofluorescence test for autoantibody to nuclear antigens (ANA): use of reference sera of defined antibody specificity. Am J Clin Pathol 82: 57-66, 1984.

24. Tan EM, Rodnan GP, Garcia I, Moroi Y, Friysler MJ, Peebles C: Diversity of antinuclear antibodies in progressive systemic sclerosis. Arthritis Rheum 23: 617-25, 1980.

25. Wilson MR, Sanders RD: Immunodiffusion assays for antibodies to small nuclear ribonucleoproteins and other cellular antigens. In: Manual of Clinical Laboratory Immunology. Rose NR, Macario EC, Fahey JL, Friedman H, Penn GM (Ed). American Society for Microbiology: Washington 741-6, 1992.

26. Orfao A, Buitrago JMG: Detectión y cuantificación de antígenos celulares. In: La citometría de flujo en el laboratorio clínico. Ribó FA (Ed). Vigor: Salamanca 31-51, 1995.

27. Frieri M, Channabasappa A, Paolano A, et al: Altered T cell subpopulations and lymphocytes expressing natural killer cell phenotypes in patients with progressive systemic sclerosis. J Allergy Clin Immunol 87: 773-9, 1991.

28. Umehara $H$, Kumagai S, Ishida $H$, Suginoshita $T$, Maeda M, Imura $\mathrm{H}$ : Enhanced production of interleukin-2 in patients with progressive systemic sclerosis. Hyperactivity of CD4-positive T cells? Arthritis Rheum 31: 401-7, 1988.

29. Postlethwaite AE: Early immune events in scleroderma. Rhem Dis Clin North Am 16: 125-39, 1990.

30. Dau PC, Callahan JP: Immune modulation during treatment of systemic sclerosis with plasmapheresis and immunosuppressive drugs. Clin Immunol Immunopathol 70: 159-65, 1994.
31. Gerli R, Agea E, Bertotto A: Analysis of T cells bearing different isotypic forms of the gd $\mathrm{T}$ cell receptor in patients with systemic autoimune diseases. J Rheumatol 18: 1504-10, 1991.

32. Giacomelli R, Matucci-Cerinic M, Cipriani P, et al: Circutating $\mathrm{Vd} 1+\mathrm{T}$ cells are activated and accumulate in the skin of systemic sclerosis patients. Arthritis Rheum 41: 327-34, 1998.

33. Kahaleh MB, Fan PS, Otsuka T: Gammadelta receptor bearing $T$ cells in scleroderma: enhanced interaction with vascular endothelial cells in vitro. Clin Immunol 91: 188-95, 1999.

34. Mitchell H, Bolster MB, LeRoy EC: Scleroderma and related conditions. Med Clin North Am 22: 751-64, 1997

35. Rizou C, Ioannidis JP, Panou-Pomonis E, et al: B-cell epitope mapping of DNA topoisomerase I defines epitopes strongly associated with pulmonary fibrosis in systemic sclerosis. Am J Respir Cell Mol Biol 22: 344-51, 2000.

36. Fiocco U, Rosada M, Cozzi L, et al: Early phenotypic activation of circulating helper memory $\mathrm{T}$ cells in scleroderma: correlation with disease activity. Ann Rheum Dis 52: 272-77, 1993.

37. Kahan A, Kahan A, Picard F, Menkes CJ, Amor B: Abnormalities of $\mathrm{T}$ lymphocyte subsets in systemic sclerosis demonstrated with anti-CD45RA and anti-CD29 monoclonal antibodies. Ann Rheum Dis 50: 354-58, 1991.

38. Sato S, Hasegawa M, Fujimoto M, Tedder TF, Takehara K: Quantitative genetic variation in CD19 expression correlates with autoimmunity. J Immunol 165: 6635-43, 2000.

39. Tedder TF, Sato S,PoeJC, Fujimoto M: CD19 and CD22 regulate a B lymphocyte signal transduction pathway that contributes to autoimmunity. Keio J Med 49:1-13, 2000

40. Kantor TV, Whiteside TL, Friberg D, Buckingham RB, Medsger Jr TA: Lymphokine-activated killer cell and natural killer cell activities in patients with systemic sclerosis. Arthritis Rheum 35: 694-99, 1992.

41. Famulano G, Quintieri F, D'Ambrosio A, Pizzuto F, Giacomelli R, Pugliese O, Tonietti G: Espansione dele cellule NK CD56+ com ridotta citotossicità in una paziente affetta da sclerosi sistemica. Recenti Prog Med 83:18-20,1992.

42. Miller EB, Hiserodt JC, Hunt LE, Steen VD, Medsger Jr TA: Reduced natural killer cell activity in patients with systemic sclerosis: correlation with clinical disease type. Arthritis Rheum 31: 151523,1988 . 